REVISTA DE DERECHO UNED, NÚM. 26, 2020

\title{
EL PAPEL DEL FISCAL DE CONSUMO. SU ACTUACIÓN EN EL PROCESO CIVIL EN DEFENSA DE CONSUMIDORES Y USUARIOS
}

\section{THE ROLE OF THE CONSUMER PROSECUTOR. HIS ACTION \\ IN THE CIVIL PROCESS IN DEFENSE OF CONSUMERS AND USERS}

\author{
Juan Bautista Calero Olmo \\ Ldo. En CC. EE. y Empresariales \\ Ldo. En Derecho. \\ Doctorando U.N.E.D.
}

Resumen: Este trabajo lo circunscribo dentro de las potenciales actuaciones procesales que el Ministerio fiscal tiene en el área de protección de los derechos de los consumidores y en el ámbito del derecho civil privado, tratadas, principalmente, por dos circulares emitidas por la Fiscalía General del Estado (FGE) y numeradas $2 / 2010$ y 2/2018. Dejando de lado el papel de la fiscalía en la más amplia y natural protección de fraudes y otros tipos penales y las intervenciones en defensa de los particulares, como usuarios consumidores, contra la administración pública, y aquellas otras complementarias de formación y divulgación. El Estado y las Comunidades Autonómicas han creado el marco jurídico preciso para esta protección desarrollando una amplia normativa reguladora de estas relaciones que se sustentan, en muchos casos, en el ejercicio y amparo de derechos reconocidos en leyes fundamentales.

Palabras clave: ministerio fiscal. Consumidor vulnerable. Fiscalía de consumo. Intervención procesal. 
Abstract: This work is limited within the potential procedural actions that the Public Prosecutor's Office has in the area of protection of consumer rights and in the field of private civil law, mainly covered by two circulars issued by State Attorney General's Office and numbered 2/2010 and 2/2018. Leaving aside the role of the public prosecutor's office in the widest and natural protection of fraud and other criminal types and interventions in defense of individuals, such as consumer users, against the public administration, and those other complementary training disclosures. The State and the Autonomous Communities have created the precise legal framework for this protection by developing a broad regulatory regulation of these relationships that are based, in many cases, on the exercise and protection of rights recognized by Fundamental laws.

Keys words: prosecutor. Vulnerable consumer. Consumer prosecution. Procedural intervention.

Recepción original:16-12-2019

Aceptación original:2-6-2020

Sumario: I. Introducción. II. El nuevo papel del Ministerio Fiscal como protector del consumidor vulnerable. II.1. La difícil definición del concepto consumidor vulnerable. II.2. El papel del fiscal de consumo. II.3. Breve mención a la organización y tareas de la fiscalía de consumo. III. Fuentes legitimadoras de la actuación del Ministerio Fiscal en el ámbito de los Consumidores y Usuarios. IV. El Art. 11.5 de la Ley de Enjuiciamiento Civil y la legitimación del Ministerio Fiscal en el ejercicio de cualquier acción individual o colectiva para la defensa de derechos e intereses de consumidores y usuarios. IV.1. Creación del marco procesal. IV.2. Especial trato que dispensa la Ley de Enjuiciamiento Civil a la actuación del Ministerio Fiscal en los procesos civiles en defensa de los Consumidores y Usuarios. IV.2.A. La especial Intervención Procesal. IV.2.B. La regulación de la capacidad para ser parte del proceso en base a su actuación independiente (Art. 6.1. 6\%). IV.2.C. La exención de caución. IV.3. Instrucción 1/2016 de la Fiscalía General del Estado, de 7 de enero, sobre la intervención del Fiscal en las cuestiones prejudiciales europeas. V. Propuesta de reforma en el proceso civil para la mejor protección jurídica de los consumidores y usuarios. VI.Conclusión.

\section{INTRODUCCIÓN.}

El papel que desarrolla el Ministerio Fiscal dentro del ámbito civil español de protección de los consumidores se enmarca en una 
normativa compleja, amplia y dinámica que necesita de actuaciones especializadas que den forma al sistema para su aplicación efectiva.

Normativa de protección con un marco legal amplio y complejo en sus fuentes que nos lleva a una aplicación engorrosa haciendo que los procedimientos de defensa se vuelvan ineficaces como se refleja por la propia Fiscal General del Estado en su memoria-informe del año 2017 cuando menciona las dificultades de la regulación legal de esta materia ${ }^{1}$ y reitera en el año 2018 incorporando una propuesta sobre la concreción de un procedimiento de acción colectiva regulado expresamente en la Ley de Enjuiciamiento civil y que veremos en el punto correspondiente.

Normativa de protección que no tiene más remedio que ser dinámica porque el protegido consumidor actúa en diferentes sectores donde va creando nuevas relaciones de consumo que generan, a su vez, otras situaciones de especial protección. El consumidor nace de los actos económicos, pero toma cuerpo legal en la medida que desarrolla sus actuaciones de relación contractual consumista.

La amplitud de derechos esenciales a proteger y las formas novísimas de relación consumidor-mercado, obligan a una continua generación de normas protectoras y actuaciones legislativas públicas con la pretensión de la protección de los derechos de los ciudadanos en su parcela como consumidores, pero sin conseguirlo por la enorme profusión de derechos a proteger que nacen de cada relación jurídica.

Nuevas formas de relación jurídica con contrataciones en masa de bienes y servicios generan posiciones de inferioridad contractual que vistas una a una no animan a una defensa individual del consumidor, pero ésta es la forma prioritaria que se adopta como respuesta más eficaz ante los órganos de justicia. La demanda colectiva es residual, entre otras razones, por la complejidad en la aplicación de sus sentencias estimatorias.

El consumidor en solitario no tiene capacidad o poder suficiente para defender sus intereses, aunque tenga infinidad de normas a su

1 Memoria elevada al Gobierno de SM presentada al inicio del año judicial por la Fiscal General del Estado Excma. Sra. D ${ }^{a}$ María José Segarra Crespo. Capítulo IV. Pág.936: "se pone de manifiesto y conviene destacar las dificultades de la regulación legal actual de toda esta materia, su falta de unificación y sistematicidad, dada que su regulación aparece diversificada, tanto procesalmente, como materialmente, en diversos textos legales, que impiden un exhaustivo conocimiento de la materia en sí, convirtiendo, de esta forma, dichos procedimientos, en técnicamente muy complejos, farragosos y de larga duración en el tiempo". 
favor que amparen su legitimidad. Es lo que podríamos llamar sobreprotección legal sin efectividad jurídica.

Se vuelven necesarios mecanismos de protección pública (preventivos, cautelares y tuitivos) que desembocan en la intervención pública para la protección del consumidor débil o vulnerable. El ministerio fiscal es uno de ellos.

\section{EL NUEVO PAPEL DEL MINISTERIO FISCAL COMO PROTECTOR DEL CONSUMIDOR VULNERABLE.}

\section{II.1. La difícil definición del concepto consumidor vulnerable.}

La Resolución de Parlamento Europeo de 22 de mayo de 2012 sobre una estrategia de refuerzo de los derechos de los consumidores vulnerables ${ }^{2}$, habla de la doble consideración de lo que debe ser esta política en la Unión Europea (UE): El fomento de los derechos de los consumidores para su posterior protección como valor fundamental, debe conjugarse con la especial atención para aquellos que se consideran vulnerables.

Concepto de vulnerabilidad basado, por un lado, en factores endógenos y propios de un determinado grupo de personas compuesto por aquellas que de forma permanente mantienen grados de discapacidad (edad, mental o física...) y, por otro, aquellos otros grupos que se encuentran en un "estado de impotencia temporal" provocado por factores heterogéneos como el nivel de educación, marginalidad social o actuación en sectores económicos de consumo especialmente problemáticos.

Podríamos, por tanto, hacer una diferenciación entre el consumidor que de forma permanente queda sujeto a un régimen de protección legal, primer grupo, y aquel otro al que un determinado acto de consumo lo somete temporal o sectorialmente a una situación de vulnerabilidad. Esta diferenciación hace patente la dificultad de adaptar instrumentos legales unitarios o globales de protección del consumidor.

Unos y otros precisan de una especial protección que tenga en cuenta las capacidades, necesidades y circunstancias concretas. El concepto de "consumidor medio" no es lo suficientemente amplio y,

2 Resolución de Parlamento Europeo de 22 de mayo de 2012 sobre una estrategia de refuerzo de los derechos de los consumidores vulnerables. (2011/2272(INI)) (2013/C $264 \mathrm{E} / 03)$. 
en algunos casos, no se corresponde con "las situaciones de la vida real"

La primera aclaración que me atrevo - por tanto- a hacer, es que el apelativo de vulnerabilidad es un término que si bien, y con relación a una especialísima protección, es inherente al concepto de consumidor, no es una consecuencia directa de éste, sino que aparece, con frecuencia, como una ampliación de este concepto ante situaciones extremas provocadas por relaciones contractuales que se fracturan anticipadamente, en la mayoría de los casos por la resolución de contratos que se hicieron para disponer de bienes de primera necesidad.

Los Tribunales, tanto nacionales ${ }^{3}$ como europeos, y, posteriormente las leyes sectoriales que regulan el consumo de estos bienes de primera necesidad son los que despliegan esta especialísima protección y lo hacen graduando el acto de consumo en función de que se trate de un consumidor de los catalogados de tipo medio, informado y formado que toma plena conciencia de lo contratado, o de aquel que por su situación de vulnerabilidad social no es capaz de prestar un consentimiento pleno.

Y así es considerado este nuevo concepto que va introduciéndose en la legislación social sobre protección del consumidor como "vulnerable", tanto en el ámbito de la exclusión social como en el envejecimiento de la población, definido por la normativa comunitaria en sus distintos planes generales de protección del consumidor, en concreto el Programa plurianual de consumidores para el periodo 20142020, como tarea transversal, dentro de los nuevos "retos" sociales.

Las propias definiciones que hacen las leyes españolas de protección del consumidor vulnerable avalan esta disquisición porque lo que hacen es referenciar la vulnerabilidad o a un determinado nivel de renta o a colectivos determinados - por ejemplo, personas mayores de 65 años-.

El propio dinamismo del marco jurídico del derecho de protección a los consumidores, junto con la especial protección del consumo en sectores de primera necesidad para colectivos en situación de exclusión social, hace muy difícil llegar a un concepto general a priori de consumidor vulnerable, aunque sí sea fácil definir las características de estos colectivos.

3 Entre muchas: STS 2244/2017. Fecha: 08/06/2017. No de Resolución: 367/2017. Ponente: Excmo. Sr. D. Rafael Sarazá Jimena. Resumen: Acción de nulidad de cláusula suelo en préstamo hipotecario. Control de transparencia. Importancia de la información. 


\section{II.2. El papel del fiscal de consumo.}

El consumidor vulnerable, es, por tanto, un concepto que se desarrolla tanto en su aspecto subjetivo como individuo merecedor de mantener niveles ordinarios de vida digna, como en el aspecto objetivo de sujeto con derecho a la tenencia y disfrute de bienes esenciales, y ha sido continuamente la base de la regulación legal de protección en los escenarios más asiduos de intervención pública.

El ministerio fiscal adquiere ahora un papel nuevo fuera del tradicional como acusador público ${ }^{4}$ y que se ha visto incrementado por los innumerables procesos provocados por la crisis financiera, con gran incidencia en los derechos fundamentales que ampara la Constitución. Señalo los artículos 10 (dignidad de la persona) y 47 (vivienda digna y adecuada) como los más dañados y sobre los que, en su protección, se ha desplegado una normativa contundente para su preservación y no exclusión de colectivos en el umbral de subsistencia.

El propio Fiscal General del Estado se hace eco de este papel en su memoria del año 2017 como un nuevo estereotipo del Fiscal en su actuación extraprocesal con la necesaria participación de este representante público en asuntos con repercusión para los intereses generales y en la defensa de los colectivos que "presenten circunstancias de especial vulnerabilidad".

Pero aquí no me refiero a la defensa del interés público común de la sociedad sino a la calificación de los bienes e intereses protegidos como esenciales para la sobrevivencia de personas o grupos de personas concretos que no alcanzan, por sí mismos, niveles mínimos de vida digna.

La circular 2/2018 sobre nuevas directrices en materia de protección jurídica de los derechos de los consumidores y usuarios emitida por la Fiscalía General del Estado, en relación con esta especial protección y las dificultades, que por sus circunstancias concretas, estos individuos tienen a la hora de iniciar contenciosos en defensa de sus intereses, señala como "La labor del MF entronca con la posibilidad de acceso a la vía judicial" de estos colectivos permitiendo reequilibrar estas situaciones de "inferioridad, indefensión o desprotección".

Actuación, por tanto, que la propia circular condiciona a que sea un mecanismo eficaz (Art. 51.1 CE), provoque el acceso de los ciuda-

4 Manuel Campoy-Miñarro. El Ministerio Fiscal y protección de la salud de los consumidores. Revista del Ministerio fiscal $n^{\circ} 4$. Año 2017. El papel del Ministerio Fiscal en la protección jurídica de los consumidores. Pág.43. 
danos a la justicia en condiciones de igualdad (Art.9.2 CE), el acceso a la tutela judicial efectiva (Art.24 CE) y en el marco y bajo los principios de legalidad e imparcialidad.

Protección de ámbito complejo, que radica, como señalábamos más arriba, tanto en la diversidad de fuentes legales a tener en cuenta como en la infinidad de intereses individuales o grupales a proteger que pueden aparecer en el ámbito contractual de los actos de consumo, pero también en otras circunstancias como la propia coordinación de los Fiscales delegados de las Comunidades Autónomas (CCAA) o la competencia territorial del propio órgano jurisdiccional.

Así nos podemos referir, como ejemplo, a las leyes promulgadas para la protección de los deudores hipotecarios que, como consecuencia de la crisis inmobiliaria en España, intentan evitar o por lo menos paliar las situaciones extremas en las que se han visto estas personas que necesitaban de una especial protección pública.

Los preámbulos de estas leyes definen estos conceptos de personas vulnerables ${ }^{5}$ que en el ámbito de la contratación hipotecaria

5 Así podemos deducir del preámbulo de estas leyes lo siguiente: Real decreto Ley 6/12 de 9 de Marzo de medidas urgentes de protección de deudores hipotecarios sin recursos: Ampara el derecho fundamental a la vivienda anticipando el concepto de consumidor vulnerable con el de Umbral de exclusión en su aspecto subjetivo y cambiante como personas que su situación económica les impida hacer frente a sus obligaciones hipotecarias y las elementales necesidades de subsistencia. El cumplimiento del contrato en su forma primaria se supedita al mantenimiento de derechos fundamentales (Art. 10 y 47 de la Comisión Europea. (CE).) por lo que estas circunstancias especiales --- Rebus sic stantibus --- "obligan voluntariamente" a una novación contractual o la aplicación de la dación en pago como "medio liberatorio definitivo de la deuda" anulando el principio del artículo 1911 del Código Civil. Ley 1/2013 de 14 de Mayo de medidas para reforzar la protección a los deudores hipotecarios, reestructuración de deuda y alquiler social: Consumidor vulnerable y concepto de exclusión social (aspecto subjetivo) en relación con el IPREM que suspende la consecuencia directa del incumplimiento de la ejecución de la garantía sobre vivienda con la paralización de los desahucios. Modificación de la Ley hipotecaria y Ley de Enjuiciamiento Civil (LEC) introduciendo la apreciación de oficio de la existencia de cláusulas abusivas (la nulidad de éstas manteniendo íntegro el resto de obligaciones) en los contratos hipotecarios pudiendo decretar la improcedencia de la ejecución y la modificación del procedimiento de subasta y posterior deuda remanente acercándose a una regulación muy cercana a la dación en pago en el caso de vivienda habitual. Así como la regulación de un régimen sancionador en su Art. 15. Real Decreto Ley 1/2015 de 27 de febrero de mecanismo de segunda oportunidad, reducción de carga financiera y otras medidas de orden social: Obligación de los poderes públicos de mantener el bien común, seguridad jurídica y, en definitiva, justicia. Real Decreto Ley 5/2017 de 17 de marzo por el que se modifica el Real Decreto-ley 6/2012, de 9 de marzo, de medidas urgentes de protección de deudores hipotecarios sin recursos, y la Ley 1/2013, de 14 de mayo, de medidas para reforzar la protección a los deudores hipotecarios, reestructuración 
para la adquisición de su vivienda habitual, de manera excepcional y en situaciones límite, se han visto amparados por la intervención del ministerio fiscal, ejemplos mencionados en la memoria de la Fiscalía General del Estado del año 2018, como la intervención de la Fiscalía Provincial de Jaén sobre la personación en procedimientos de desahucios contra familias "especialmente vulnerables por minoría de edad y/o discapacidad usando el RD Ley 15/2017, de 17 de marzo", o la Fiscalía Provincial de Valencia iniciando una acción co-

de deuda y alquiler social: Colectivos especialmente vulnerables, traspasando el carácter subjetivo de vulnerabilidad individual a la colectiva como consumidores que atraviesan situaciones de especial debilidad. Real Decreto 897/2017, de 6 de octubre, por el que se regula la figura del consumidor vulnerable, el bono social y otras medidas de protección para los consumidores domésticos de energía eléctrica. De esta forma, el presente real decreto define la figura del consumidor vulnerable, asociándola, como regla general, a determinados umbrales de renta referenciados al Indicador Público de Renta de Efectos Múltiples (IPREM), en función del número de miembros que compongan la unidad familiar. Estos umbrales pueden verse incrementados si se acredita la concurrencia en uno de los miembros de la unidad familiar de determinadas circunstancias especiales. Adicionalmente, se reconoce a determinados colectivos la percepción del bono social con independencia de su nivel de renta. Dentro de los consumidores vulnerables, se establece un bono social de mayor cuantía para los consumidores vulnerables severos, que son definidos por referencia a umbrales de renta más bajos que los señalados con carácter general. Se crea además una categoría diferenciada dentro de los consumidores vulnerables severos, a saber, los consumidores en riesgo de exclusión social, que serán aquellos que, cumpliendo los umbrales de renta de aplicación, estén siendo atendidos por los servicios sociales de una Administración autonómica o local en los términos previstos en este real decreto. Para tener la condición de consumidor vulnerable severo en riesgo de exclusión social, y de conformidad con el Real Decreto-ley 7/2016, de 23 de diciembre, el real decreto determina que el coste de su factura eléctrica deberá ser cofinanciado por la Administración Pública correspondiente y por las matrices de los grupos de sociedades que desarrollen la actividad de comercialización de energía eléctrica, o por las propias sociedades que así lo hagan, si no forman parte de ningún grupo societario. Bajo estas condiciones, la presente norma determina la imposibilidad de que el suministro de este colectivo de consumidores en riesgo de exclusión social pueda verse suspendido. Ley 5/2019, de 15 de marzo, reguladora de los contratos de crédito inmobiliario. (Adaptación Directiva 2014/17/UE del Parlamento Europeo y del Consejo de 4 de febrero de 2014 sobre los contratos de crédito celebrados con los consumidores para bienes inmuebles de uso residencial y por la que se modifican las Directivas 2008/48/CE y 2013/36/UE y el Reglamento 1093/2010). La disposición final décima modifica el Real Decreto-Ley 6/2012, de 9 de marzo, de medidas urgentes de protección de deudores hipotecarios sin recursos con el fin de convertir el código de buenas prácticas en un mecanismo permanente y obligatorio para todas las entidades adheridas que permita a todos los deudores más vulnerables en situación de impago acceder a las opciones de alivio de la deuda contenidas en el mismo. ARTÍCULO: Se encuentra pendiente de transposición la Directiva 2014/17/UE de 4 de febrero de 2014 sobre los contratos de créditos celebrados con consumidores para bienes inmuebles de uso residencial. El plazo para transponerla finalizó el 21 de marzo de 2016 (fecha en la deberían estar ya publicadas las normas nacionales de transposición). El momento previsto para valorar su eficacia y adecuación finalizara el 21 de marzo de 2019. 
lectiva de cesación por prácticas abusivas y otra, sobre los derechos de los consumidores, contra Renfe en relación a la prestación del servicio de transporte a pasajeros con problemas de movilidad y discapacidad.

Memoria que sigue haciendo referencia al deber de la fiscalía con determinados grupos sociales en su representación ante los Tribunales de Justicia y en defensa, particularmente, de las personas especialmente vulnerables ${ }^{6}$.

Actuaciones, por tanto, de protección que vele por estos colectivos cuyos actos de consumo los lleve a posiciones de inferioridad en la defensa del disfrute de sus derechos fundamentales.

Podríamos, por tanto, decir que las características de actuación del Ministerio Fiscal, dentro del ámbito civil, como protector de los derechos individuales y colectivos de los consumidores y dentro de su vertiente integradora y de coordinación de actuaciones de los Tribunales, resto de poderes públicos y organizaciones público-privadas, se podrían enumerar, según la Circular 2/2018 de la Fiscalía General del Estado, en:

- Amplitud de áreas de intervención con actuación independiente a la de otros agentes públicos o privados. Estas áreas se caracterizan y engloban dentro de las situaciones de inferioridad, subordinación e indefensión, acudiendo a la vía judicial, como último recurso, con la finalidad del reequilibrio de las situaciones que pudieran producirse.

- Actuación voluntaria por decisión propia o llamado por otro órgano jurídico o agente público o privado.

- Actuación protectora necesaria de los derechos del llamado consumidor vulnerable tanto como individuo como en atención a los bienes necesarios para su vivencia ordinaria.

- Papel preventivo con especial atención a la tutela cautelar de los consumidores y usuarios.

6 Memoria elevada al Gobierno de S.M. presentada al inicio del año judicial por la fiscal general del Estado Exma. Sra. D ${ }^{a}$ María José Segarra Crespo. Volumen 1. Pág. XVIII "Sin embargo, la Memoria supone, sobre todo, un compromiso de transparencia. Nos debemos a la sociedad, a la que representamos ante los Tribunales de Justicia, en defensa de la legalidad y de los derechos de los ciudadanos, particularmente, de las víctimas y de las personas especialmente vulnerables..." 


\section{II.3. Breve mención a la organización y tareas de la fiscalía de consumo.}

La Circular 2/2018 recuerda la obligatoriedad de designar, por parte del Fiscal Jefe provincial, un fiscal encargado de la protección jurídica de los consumidores y usuarios dentro de la sección de lo Civil en aquellas Fiscalías Provinciales en que aún no se haya designado. Por tanto, de la protección jurídica de los consumidores y usuarios se encargará un fiscal provincial integrado en la sala de lo Civil que será designado por el Fiscal Jefe Provincial, que, adaptándose a la singularidad de cada territorio en volumen e identidad de los asuntos, deberá observar la formalidad prevista en la Instrucción de la fiscalía General 5/2008 de 18 de diciembre apartado I.e, esto es, previa oferta a todos los fiscales de la "correspondiente plantilla" y resolviendo a favor de aquél que haya destacado en el área de protección de los consumidores y usuarios.

La labor de estas fiscalías provinciales debe realizarse en coordinación y supervisión del Fiscal de la Comunidad Autónoma de la especialidad civil determinando cuales son las cuestiones prioritarias por tratar.

Las diligencias pre procesales que en cada ejercicio se incoen deben ser registradas, especificando la materia sobre la que versen y si han dado lugar a actuaciones procesales, y tanto unas como otras deben tener su reflejo en las memorias anuales de cada fiscalía como así se produce en la memoria del año 2018, donde se hace mención por primera vez a estas actuaciones de las distintas fiscalías de las Comunidades Autónomas o provinciales. ${ }^{7}$.

Destaco, entre otras, las actuaciones pre procesales de la Fiscalía de Pontevedra con la presentación de una acción colectiva de cesación en defensa de los intereses difusos de los consumidores y usuarios, así como acciones de nulidad, restitución de cantidades y de indemnización de daños y perjuicios sobre el funcionamiento en obras de la autopista AP-9 y el cobro irregular de peaje; o la de la Fiscalía del Área de la Comunidad Autónoma de Ceuta con la demanda ante la empresa municipal de suministro de aguas por decidir, de forma unilateral, no enviar a los consumidores abonados factura en papel sobre el consumo realizado, que como las destacadas anteriormente, se reflejan en la memoria de la Fiscalía General del Estado del año 18.

7 Memoria Fiscal General Estado. Año 18. Pág. 1201- 1203. 


\section{FUENTES LEGITIMADORAS DE LA ACTUACIÓN DEL MINISTERIO FISCAL EN EL ÁMBITO DE LOS CONSUMIDORES Y USUARIOS.}

La figura "legalizada" del ministerio fiscal como órgano jurisdiccional para actuar en la defensa de los consumidores y usuarios, la podríamos asentar en varios encuadramientos normativos, nacionales y europeos, que lo dotan de mandatos que emanan de normas jurídicas de las denominadas de rango superior y a las que se deben adaptar el resto de las que regulan esta protección.

Principios rectores, por tanto, que se enumeran a lo largo del texto constitucional, por un lado, y la carta de los derechos fundamentales y tratado de funcionamiento de la Unión Europea (TFUE) por otro ${ }^{8}$.

Mandatos Constitucionales que van dirigidos a todos los poderes públicos y también al Ministerio Fiscal como parte del poder judicial refiriéndose a la promoción de la libertad e igualdad del individuo (Art. 9.2 CE), los principios rectores de la política social y económica (Art. 51.1 CE), los vinculados a los derechos y libertades del Título primero capítulo segundo (Art $53 \mathrm{CE}$ ), y la regulación del poder judicial, en concreto, el artículo 124 sobre el Ministerio Fiscal que lo concreta y especifica como protector de los derechos e intereses de los ciudadanos, legitimándose como órgano jurisdiccional habilitado expresamente, por este mandato constitucional, en el proceso civil.

Y expresamente habilitado también por la Ley Orgánica del Poder Judicial (Art. 7.3) y el Estatuto Orgánico del Ministerio Fiscal (Art. 1 y Art. 3 en sus puntos 1,6,7 y 9 el Art. 8 de su capítulo IV).

8 Tratado de Funcionamiento de la Unión Europea: Artículo 4.2 apartado f. Artículo 6apartado f. Título II. Disposiciones de aplicación general: Artículo 12 (antiguo artículo 153. Apartado 2 del TCE). Título XV Protección de los consumidores: Artículo 169 (Antiguo artículo 153 TCE). Carta de los derechos fundamentales de la UE: Artículo 38. Capítulo VI. Justicia: Artículo47. Reglamento (UE) no 254/2014 DEL Parlamento Europeo y del Consejo de 26 de febrero de 2014 sobre el programa plurianual de consumidores para el periodo 2014-2020 y por el que se deroga la decisión n ${ }^{\circ}$ 1926/2006/ce. Anexo I. Tipo de acciones. nº 9 y su apartado d. 


\section{El Estado ${ }^{9}$ y las Comunidades Autonómicas ${ }^{10}$ han creado el}

9 DERECHO ESTATAL: Leyes: Real Decreto-ley 23/2018, de 21 de diciembre, de transposición de directivas en materia de marcas, transporte ferroviario y viajes combinados y servicios de viaje vinculados. Ley 4/2018, de 11 de junio, por la que se modifica el texto refundido de la Ley General para la Defensa de los Consumidores y Usuarios y otras leyes complementarias, aprobado por Real Decreto Legislativo 1/2007, de 16 de noviembre. Ley $7 / 2017$, de 2 de noviembre, por la que se incorpora al ordenamiento jurídico español la Directiva 2013/11/UE, del Parlamento Europeo y del Consejo, de 21 de mayo de 2013, relativa a la resolución alternativa de litigios en materia de consumo. Ley 3/2014, de 27 de marzo, por la que se modifica el texto refundido de la Ley General para la Defensa de los Consumidores y Usuarios y otras leyes complementarias, aprobado por el Real Decreto Legislativo 1/2007, de 16 de noviembre. Ley 4/2012, de 6 de julio, de contratos de aprovechamiento por turno de bienes de uso turístico, de adquisición de productos vacacionales de larga duración, de reventa y de intercambio y normas tributarias. Ley 16/2011, de 24 de junio, de contratos de crédito al consumo. Real Decreto Legislativo 1/2007, de 16 de noviembre, por el que se aprueba el texto refundido de la Ley General para la Defensa de los Consumidores y Usuarios y otras leyes complementarias. Ley 22/2007, de 11 de julio, sobre comercialización a distancia de servicios financieros destinados a los consumidores. Ley 44/2006, de 29 de diciembre, de mejora de la protección de los consumidores y usuarios. Ley 59/2003, de 19 de diciembre, de firma electrónica (BOE de 20 de diciembre de 2003, núm. 304/2003). Ley 47/2002, de 19 de diciembre, de reforma de la Ley 7/1996, de 15 de enero, de ordenación del comercio minorista, para la transposición al ordenamiento jurídico español de la Directiva 97/7/ce, en materia de contratos a distancia, y para la adaptación de la ley a diversas Directivas comunitarias. Ley 40/2002, de 14 de noviembre, reguladora del contrato de aparcamiento de vehículos. Ley 39/2002, de 28 de octubre, de transposición al ordenamiento jurídico español de diversas directivas comunitarias en materia de protección de los intereses de los consumidores y usuarios. Ley 34/2002, de 11 julio, de servicios de la sociedad de la información y de comercio electrónico. Ley 28/1998, de 13 de julio, de venta a plazos de bienes muebles. Ley 7/1998, de 13 abril, sobre condiciones generales de la contratación. Ley 7/1996, de 15 de enero, de ordenación del comercio minorista. Ley 3/1991, de 10 enero, de competencia desleal. Ley 34/1988, de 11 de noviembre, general de publicidad. REALES DECRETOS: Real Decreto 199/2010, de 26 de febrero, por el que se regula el ejercicio de la venta ambulante o no sedentaria. Real Decreto 231/2008, de 15 de febrero, por el que se regula el Sistema Arbitral de Consumo. Real Decreto 894/2005, de 22 de julio, por el que se regula el Consejo de Consumidores y Usuarios. Real Decreto 1801/2003, de 26 de diciembre, sobre seguridad general de los productos. Real Decreto 1507/2000, de 1 septiembre, por el que se actualiza los catálogos de productos y servicios de uso o consumo común, ordinario y generalizado y de bienes de naturaleza duradera, a efectos de lo dispuesto en los artículos 2.2, 11.2 y 11.5, de la Ley general para la defensa de los consumidores y usuarios y normas concordantes. Real Decreto 1828/1999, de 3 de diciembre, por el que se aprueba el Reglamento del Registro de condiciones generales de la contratación. Real Decreto 825/1990, de 22 de junio, sobre el derecho de representación, consulta y participación de los consumidores y usuarios a través de sus asociaciones. Real Decreto 820/1990, de 22 de junio, por el que se prohíbe la comercialización y fabricación de los productos de apariencia engañosa que pongan en peligro la salud o seguridad de los consumidores. Real Decreto 515/1989, de 21 de abril, sobre protección de los consumidores en cuanto a la información a suministrar en la compraventa y arrendamiento de viviendas. Real Decreto 1468/1988, de 2 de diciembre, por el que se aprueba el reglamento de etiquetado, presentación y publicidad de los productos industriales destinados a su venta directa a los consumidores y usuarios. Real Decreto 1945/1983, de 22 de junio, por el que se regulan las infracciones y sanciones en materia de defensa del consumidor y de la producción agroalimentaria.

10 DERECHO AUTONÓMICO: Andalucía-Ley 13/2003, de 17 de diciembre, de defensa y protección de los consumidores y usuarios de Andalucía. Aragón-Ley 
marco jurídico preciso para esta protección, desarrollando una amplia normativa reguladora de estas relaciones que se sustentan, en muchos casos, en el desarrollo del ejercicio de los derechos fundamentales reconocidos en la Constitución.

Mandatos europeos que se definen tanto en la Carta de los Derechos Fundamentales de la Unión Europea, en su Art. 38 con la protección de los consumidores como derecho fundamental, y en el Capítulo IV su Art. 47 cuando se refiere al derecho a la tutela judicial efectiva.

Como en el tratado de funcionamiento de la Unión Europea (Art. $12,67.4,81.2 \mathrm{e})$ y en concreto, en el título XV dedicado a la protección de los consumidores, cuando habla, en su artículo 169, de derechos a proteger como la salud, seguridad, intereses económicos, derecho a la información, educación y organización precisa para salvaguardar estos intereses.

Derechos que se incluyeron en el Reglamento (UE) $\mathrm{N}^{\circ}$ 254/2014 del Parlamento Europeo y del Consejo de 26 de febrero de 2014 sobre el Programa plurianual de Consumidores para el período 20142020 plasmado, por primera vez, en forma de reglamento de obligado cumplimiento por los estados miembros, donde destacan su objetivo III y IV

El objetivo III por el desarrollo y fortalecimiento de los derechos de los consumidores a través de "una intervención legislativa inteli-

16/2006, de 28 de diciembre, de protección y defensa de los consumidores y usuarios de Aragón. Canarias-Ley 3/2003, de 12 de febrero, del Estatuto de los consumidores y usuarios de la Comunidad Autónoma de Canarias. Cantabria-Ley 1/2006, de 7 de marzo, de defensa de los consumidores y usuarios. Castilla-La ManchaLey 3/2019, de 22 de marzo, del Estatuto de las personas consumidoras en Castilla-La Mancha. Castilla y León-Ley 2/2015, de 4 de marzo, por la que se aprueba el Estatuto del Consumidor de Castilla y León. Cataluña-Ley 22/2010, de 20 de julio, del Código de consumo de Cataluña. Comunidad Valenciana-Ley 1/2011, de 22 de marzo, por el que se aprueba el Estatuto de los consumidores y usuarios de la Comunidad Valenciana. Extremadura-Ley 6/2019, de 20 de febrero, del Estatuto de las personas consumidoras de Extremadura. Galicia-Ley 2/2012, de 28 de marzo, gallega de protección general de las personas consumidoras y usuarias. Illes BalearsLey 7/2014, de 23 de julio, de protección de las personas consumidoras y usuarias de las Illes Balears. La Rioja-Ley 5/2013, de 12 de abril, para la defensa de los consumidores en la Comunidad Autónoma de La Rioja. Madrid-Ley 11/1998, de 9 de julio, de protección de los consumidores y usuarios de la Comunidad de Madrid. Navarra-Ley 7/2006, de 20 de junio, de defensa de los consumidores y usuarios. País Vasco-Ley 2/2012, de 9 de febrero, por la que se modifica la Ley 6/2003. Principado de Asturias-Ley 11/2002, de 2 de diciembre, de los consumidores y usuarios, del Principado de Asturias. Región de Murcia-Ley 1/2008, de 21 de abril, por la que se modifica la Ley 4/1996. 
gente", con tipo de acciones concretas que se mencionan en el anexo I-número 9 "prestando especial atención a las medidas adecuadas que atiendan las necesidades y los derechos de los consumidores vulnerables" con el desarrollo de herramientas específicas.

Y el objetivo IV por el desarrollo de acciones destinadas a mejorar la cooperación entre las autoridades, apoyando el ejercicio de los derechos de los consumidores.

Uno y otro, objetivo III y IV, han sido ya, en cierta medida, contemplados en nuestro ordenamiento con la creación de la figura del "fiscal de consumo" anticipado por la circular 2/2010 de la Fiscalía General del Estado y desarrollada, en lo que corresponde a la organización del servicio, por la circular del mismo órgano 2/2018.

\section{EL ART. 11.5 DE LA LEY DE ENJUICIAMIENTO CIVIL Y LA \\ LEGITIMACIÓN DEL MINISTERIO FISCAL EN EL EJERCICIO DE CUALQUIER ACCIÓN INDIVIDUAL O COLECTIVA PARA LA DEFENSA DE DERECHOS E INTERESES DE CONSUMIDORES Y USUARIOS.}

Atribución de legitimación al Ministerio Fiscal en el orden civil para la defensa y protección de los consumidores y usuarios con cobertura normativa en el Art. 124 de la Constitución Española, artículos 3.6, 3.9 y 16 del Estatuto orgánico del Ministerio Fiscal, así como el 11.5 de la Ley de enjuiciamiento civil (LEC) que lo habilita para el ejercicio de cualquier acción para la defensa de los intereses de los consumidores y usuarios.

\section{IV.1. Creación del marco procesal.}

La Ley 39/2002 de transposición al ordenamiento jurídico español de diversas directivas comunitarias en materia de protección de los intereses de los consumidores y usuarios, incorporó al ordenamiento Español la Directiva 98/27/CE de 19 de mayo de 1998 relativa a las acciones de cesación modificando, entre otras leyes sectoriales ${ }^{11}$, la Ley de Enjuiciamiento Civil, con la incorporación de un

11 Ley de 7/1998, de 13 de abril, de Condiciones Generales de la Contratación. El artículo 16.6 Legitimación activa. El Ministerio Fiscal. Ley 26/1984, de 19 de julio General para la Defensa de los Consumidores y Usuarios. Primero. Se adiciona un nuevo artículo 10 ter.3. Estarán legitimados para ejercitar la acción de cesación. c) El Ministerio Fiscal. Ley 26/1991, de 21 de noviembre sobre contratos celebrados fuera de los establecimientos mercantiles. Se añade un artículo 10. Acción de cesa- 
apartado 4 al artículo 11, estableciendo por primera vez un "marco procesal" adecuado para la legitimación del ministerio fiscal en el ámbito de estas acciones.

Sin embargo, como señala la propia circular 2/2010 de la Fiscalía General del Estado acerca de la intervención del Ministerio Fiscal en el orden civil para la protección de los Consumidores y Usuarios, existían dificultades interpretativas a la hora de considerar que el Ministerio Fiscal resultase legitimado en la Ley de Enjuiciamiento Civil "para ejercitar acciones colectivas distintas a la de cesación, particularmente la de resarcimiento de daños a que se refiere el artículo 11 de la LEC", por lo que se proponía la modificación de este artículo incorporando un nuevo apartado en el que se contemplara la legitimación del Ministerio Fiscal en un sentido más amplio para el ejercicio de cualquier acción en defensa de los consumidores y Usuarios.

Además de lo anterior, se producía una contradicción entre la normativa en materia de consumo, principalmente el texto refundido de la Ley General para la Defensa de los Consumidores y Usuarios-Art. 54, y la procesal con relación a las Entidades que deben estar legitimadas para interponer la acción de cesación.

Esta contradicción se resolvió con la publicación de la Ley 3/2014 de 27 de marzo, por la que se modificaba el texto refundido de la Ley General para la Defensa de los Consumidores y Usuarios y otras leyes complementarias ${ }^{12}$ a fin de transponer a nuestro derecho

ción. 3. Estarán legitimados para ejercitar la acción de cesación. c) El Ministerio Fiscal. Ley 21/1995, de 6 de julio reguladora de los Viajes Combinados. Se modifica el artículo 13. Acción de cesación.3. Estarán legitimados para ejercitar la acción de cesación. c) El Ministerio Fiscal. Ley 42/1998, de 15 de diciembre, sobre derechos de aprovechamiento por turno de bienes inmuebles de uso turístico y normas tributarias. Se modifica la rúbrica del capítulo III del Título I y se le adiciona un artículo 16 bis, con la siguiente redacción. 3. Estarán legitimados para ejercitar la acción de cesación. c) El Ministerio Fiscal. Ley 25/1990, de 20 de diciembre, del Medicamento. Con la rúbrica «De la acción de cesación», se adiciona un nuevo Título XI. Artículo 121. Acción de cesación. 3. Estarán legitimados para ejercitar la acción de cesación. c) El Ministerio Fiscal. Ley 25/1994, de 12 de julio, por la que se incorpora al ordenamiento jurídico español la Directiva 89/552 CEE, sobre la coordinación de disposiciones legales, reglamentarias y administrativas de los Estados miembros relativas al ejercicio de actividades de radiodifusión televisiva. Se añade un nuevo capítulo VII. «Artículo 22. Acción de cesación. 3. Estarán legitimados para ejercitar la acción de cesación. c) El Ministerio Fiscal.

12 Ley 1/2000, de 7 de enero, de Enjuiciamiento Civil: Incorporación artículo 11.4. Se modifica el apartado 4 y se añade el apartado 5 por la disposición adicional 2 de la Ley 3/2014, de 27 de marzo. Ref. BOE-A-2014-3329. - Ley 7/1998, de 13 de abril, sobre condiciones generales de la contratación: Art. 16.6 para el ejercicio de las acciones previstas en el artículo 12. - Real Decreto Legislativo 1/2007, de 16 
interno la Directiva 2011/83/UE de 25 de octubre de 2011 sobre los derechos de los consumidores, incorporando un nuevo ordinal 5 al artículo 11 de la LEC con el que se dotaba de legitimación de la actuación al Ministerio Fiscal en el ejercicio de cualquier acción (individual o colectiva) en defensa de los intereses de los consumidores y usuarios.

A partir de aquí, El Fiscal adquiere un amplísimo margen procesal que, dados los innumerables litigios que se están abriendo en estos días, haría imposible su actuación eficaz, haciendo necesario, bajo el principio de independencia, marcar áreas de actuación prioritarias, que el propio Fiscal General del Estado a través de la obligada circular 2/2018, condiciona a la valoración concreta de la situación y la inexistencia de otros mecanismos eficaces que eviten la judicialización del conflicto.

\section{IV.2. Especial trato que dispensa la Ley de Enjuiciamiento Civil a la actuación del Ministerio Fiscal en los procesos civiles en defensa de los Consumidores y Usuarios.}

Como venimos diciendo, la posición del consumidor toma juego cuando se integra en un ámbito contractual que regula los bienes o servicios a percibir tanto desde su posición como sujeto preceptor de derechos fundamentales regulados en las distintas fuentes legales, como en los bienes o servicios que sustentan o provocan estos derechos y todo esto dentro de los sectores oferentes concretos.

de noviembre, por el que se aprueba el texto refundido de la Ley General para la Defensa de los Consumidores y Usuarios y otras leyes complementarias: Art. 54.1.c para el ejercicio de las acciones mencionadas en el artículo 53. - Ley 26/91 de 21 de noviembre de contratos celebrados fuera del establecimiento mercantil: Se añade un artículo 10 destacando en el apartado 3.C. - Ley 21/1995 de 6 de junio. Reguladora de viajes combinados: Se modifica el Art. 13 incorporando, entre otros, el apartado 3.C. - Ley 42/1998 de 15 de diciembre sobre aprovechamiento por turno de bienes inmuebles de uso turístico y normas tributarias: Se añade el Artículo 16.Bis punto 3.C - Ley 25/1990de 20 de diciembre del medicamento. Derogada por Real Decreto Legislativo 1/2015, de 24 de julio, por el que se aprueba el texto refundido de la Ley de garantías y uso racional de los medicamentos y productos sanitarios.1/2015 de 24 de julio: En su artículo 118.3.C - Ley 34/1988 de 11 de noviembre. General de la publicidad: Añade el Art. 29 punto 3.C - Ley 7/1995 de 23 de marzo e crédito al consumo derogada por la Ley 16/2011 de 24 de junio de contratos de crédito al consumo: Artículo 36 lo previsto en los artículos 53, apartados 1 y 2 del 54, 55 y 56 del texto refundido de la Ley General para la Defensa de los Consumidores y Usuarios y otras leyes complementarias, y, en lo no previsto por ésta, será de aplicación la Ley 1/2000, de 7 de enero, de Enjuiciamiento Civil. 
En lo referente a los procesos en los que intervienen consumidores y usuarios, habida cuenta de la especial protección de éstos en distintas leyes que configuran su marco amplio y disperso de protección, la ley procesal también regula una serie de artículos especiales.

El propio preámbulo de la Ley de Enjuiciamiento Civil destaca estas especialidades procesales en los campos de la apreciación de la capacidad y legitimación para ser parte, en la competencia territorial con amplio margen de elección por parte del consumidor en el ejercicio de acciones individuales, en lo relativo a la acumulación de procesos con clara determinación de las causas de su no procedencia, en los efectos y especialidad de las sentencias en los procesos promovidos por las asociaciones de consumidores con la identificación de los beneficiarios y la extensión de la cosa juzgada material a sujetos no litigantes, la especialidad en el procedimiento buscando rápidas resoluciones en el caso de solicitud de acciones de cesación, la regulación de las diligencias preliminares para la efectiva determinación de los grupos de afectados y de la exención de la caución en la solicitud de medidas cautelares para el efectivo ejercicio de la acción de cesación incorporando multas coercitivas en su incumplimiento.

Y por último, en el juicio ejecutivo con la oposición por cláusula abusiva dentro de las razones tasadas previstas en el apartado $7 .^{\mathrm{a}}$ del artículo 557.1 y 4. ${ }^{a}$ del artículo 695.1 de la LEC y prorrogadas con el nuevo incidente extraordinario de oposición introducido por la Disposición Transitoria $3^{\text {a }}$ de la Ley 5/2019 de 15 de marzo, reguladora de los contratos de crédito inmobiliario y la apreciación de oficio de estas cláusulas por parte del juez en la admisión de la demanda tanto individual como colectiva.

En concreto, con respecto al papel especial del fiscal se podrían destacar:

\section{IV.2.A. La especial Intervención Procesal.}

Varios son los casos en los que el Fiscal sin haber sido demandante (Art. 13.1 LEC) puede intervenir en las acciones tanto de control preventivo y abstracto, de resarcimiento de daños $u$ otras que obliguen a cesar en una conducta y prohibir su reiteración futura o, caso de condiciones generales contractuales, impidan recomendar o suscribir determinadas cláusulas. 
Intervención voluntaria o provocada por el propio Tribunal que trasciende la tradicional adhesiva simple o litisconsorcial porque el Ministerio Público, con su participación garantiza la efectividad de las normas, la seguridad jurídica, la igualdad ante la Ley y una interpretación unitaria del ordenamiento. Las razones de ser de su encomienda constitucional.

Con respecto a la amplitud de áreas de intervención, con especial mención a la acción ejecutiva de consumidores y usuarios fundamentada en sentencias de condena sin determinación individual de los beneficiarios buscando la efectividad jurídica del proceso (Art. 519-último párrafo.)

La "invitación" obligatoria a la intervención en los supuestos de acción colectiva del artículo 15 de la LEC, último párrafo del punto primero, como actuación protectora e introducida por la Ley 29/2009, de 30 de diciembre, por la que se modifica el régimen legal de la competencia desleal y de la publicidad para la mejora de la protección de los consumidores y usuarios, en los que el Tribunal debe comunicar al MF los procesos que conozca cuando el interés social los justifique y éste valorará "el interés social" de su actuación $\mathrm{y}$, por tanto, la posibilidad de personarse.

\section{IV.2.B. La regulación de la capacidad para ser parte del proceso en base a su actuación independiente (Art. 6.1. $6^{\circ}$ ).}

Por su especial misión constitucional (Art 124.1 CE) y sólo en aquellos casos en los que conforme a la Ley haya de intervenir como parte. En nuestro campo de consumidores y usuarios, aquellos que se refieran al consumidor "vulnerable" y como protector, en el campo del consumo, de aquellos bienes y servicios fundamentales para mantener los niveles de vida apropiados.

\section{IV.2.C. La exención de caución.}

Tanto en la regulación de las diligencias preliminares para la efectiva determinación del grupo de afectados del Art. 256.1. $6^{\circ}$ LEC, o la solicitud de medidas cautelares del Art. 728 LEC. 


\section{IV.3. Instrucción 1/2016 de la Fiscalía General del Estado, de 7 de enero, sobre la intervención del Fiscal en las cuestiones prejudiciales europeas.}

Es interesante acercarnos a la participación del Fiscal en las cuestiones prejudiciales sobre protección de consumidores y usuarios propuestas ante el Tribunal de Justicia de la Unión Europea (TJUE) relativas a la interpretación unitaria del Derecho de la Unión y sobre la validez de los actos adoptados por las instituciones, órganos u organismos europeos.

Con carácter general, estas cuestiones están reguladas en el artículo 267 del Tratado de Funcionamiento de la Unión Europea (TFUE) y desarrolladas en el Título Tercero- De las Cuestiones Prejudiciales-artículos 93 al 118 del Reglamento de Procedimiento del Tribunal de Justicia de la Unión Europea.

La Fiscalía General del Estado, mediante la instrucción 1/2016 aclara que, con carácter general, corresponde al Juez nacional que conoce del litigio apreciar la necesidad y pertinencia del planteamiento de la cuestión prejudicial y que la participación del Ministerio Fiscal en estas cuestiones, solo podrá darse, en el ámbito civil, cuando sea parte del procedimiento, dictaminando obligatoriamente, con criterio jurídico, sobre aquellas cuestiones amparadas por el art. 124 de la Constitución en defensa de la legalidad, de los derechos de los ciudadanos y del interés público.

Pero el apartado 5 del artículo 11 de la LEC dota de legitimidad al Ministerio Fiscal para cualquier procedimiento de defensa de los derechos de los consumidores y usuarios y, por tanto, tal como señala la instrucción, se debe hablar de una doble participación,

1) Poder plantear una cuestión de prejudicialidad previa conformidad de la Fiscalía General del Estado en base a un informe "sucinto", con los razonamientos legales sobre las consecuencias de la aplicación o no de la norma o ...

2) Obligatoriamente, si apreciare interés social en la cuestión prejudicial aunque no se hubiera constituido como parte, emitiendo dictamen ante el órgano judicial con una doble finalidad: aportar criterios jurídicos de peso para determinar o no la decisión de presentar la cuestión, y de otra, asegurar una unidad de actuación para todos los órganos judiciales en la presentación de tales cuestiones. Pero, como hemos dicho, y tal como aclara la circular 2/2010 y recuerda la 2/2018, el dictamen se limita a los casos en los que se aprecie un interés social en el sentido de público que "conecta con el 
Capítulo III del Título I de la Constitución que se refiere a los principios rectores de la política social y económica, contenidos en los arts. 48 a 53 CE".

Aunque en última instancia, la decisión de plantear la cuestión corresponde al Tribunal, cuando éste no identifica correctamente las normas europeas sobre las que se suscita la cuestión prejudicial o cualquier otra razón que impida valorar la procedencia del planteamiento, el Ministerio Público, tiene un tercer papel y deberá, en este caso, interponer recurso recurriendo la providencia de traslado, e incluso, en el caso de que ni siquiera a través del recurso se aclararan tales cuestiones, debe informar al TJUE que no procede el planteamiento de la cuestión por no existir dudas razonables sobre la interpretación de la cuestión o no resulta necesario por no contradecir, la normativa nacional o propia jurisprudencia, a la normativa comunitaria.

\section{PROPUESTA DE REFORMA EN EL PROCESO CIVIL PARA LA MEJOR PROTECCIÓN JURÍDICA DE LOS CONSUMIDORES Y USUARIOS.}

La Memoria de la Fiscalía General del Estado del ejercicio 2018, publicada el año 2019, introduce una serie de propuestas de modificación del Derecho Procesal Civil que redundaría, según el propio informe, en una mejora del procedimiento de actuación general que la Ley de Enjuiciamiento Civil presta a las especiales actuaciones de protección de los consumidores y usuarios.

No se trata de propuestas o de demandas de reforma general en campos concretos de la Ley de Enjuiciamiento Civil, sino de la Introducción de un procedimiento colectivo de consumo agrupando las leyes especiales con las diversas disposiciones dispersas dentro de la LEC en base a la nueva propuesta de Directiva del Parlamento Europeo y del Consejo relativa a las acciones de representación para la protección de los intereses colectivos de los consumidores y por la que se deroga la Directiva 2009/22/CE de 23 de abril de 2009, relativa a las acciones de cesación en materia de protección de los intereses de los consumidores.

Las líneas generales de este nuevo enfoque podrían resumirse:

Este unitario procedimiento colectivo debería concretar su ámbito de actuación tanto desde el punto de vista objetivo como subjetivo. En el primero aclarando si "únicamente se aplica en los casos 
en los que un solo hecho perjudica a una pluralidad de consumidores o si, por el contrario, puede extenderse a una pluralidad de hechos homogéneos igualmente lesivos" ${ }^{13}$, y en el segundo aclarando si un número reducido de perjudicados justificaría la apertura de este procedimiento.

Así mismo, determinar la posibilidad de extender la eficacia del proceso del control en abstracto de las condiciones contractuales abusivas a una pluralidad de contratos o preverse filtros para evitar demandas colectivas que "persigan fines espurios".

Introducir una previsión legal específica en el Título sexto del libro III sobre medidas cautelares de naturaleza anticipatoria cuando se ejerciten, sobre todo, acciones de cesación.

Regular la carga desproporcionada de comunicación a todos los afectados prevista en el artículo 15.2 sobre publicidad del proceso y cambiarla por un llamamiento posterior mediante anuncios en los medios de comunicación.

Sobre la eficacia de la sentencia frente a terceros no personados en los procesos promovidos por las Asociaciones de Consumidores y Usuarios, se trataría de aclarar en la propia Ley los efectos de las sentencias estimatorias tanto frente a los perjudicados como a las empresas que no han sido demandadas según el artículo 221 LEC, extendiendo en su caso los artículos 23.2 y 31.2 de la LEC a las reclamaciones colectivas de pequeña cuantía.

En relación con la ejecución de la sentencia en los procesos colectivos donde existen multitud de damnificados, se propone para su buen fin, por parte de la Fiscalía General, la colaboración de entidades públicas "competentes" en materia de protección de consumidores e incentivarse punitivamente el cumplimiento voluntario del infractor

Resolver la discusión doctrinal provocada por el artículo 222 LEC, positivando legalmente la jurisprudencia tanto del Tribunal Supremo como del Tribunal Constitucional, y entendemos que también la correspondiente al Tribunal de justicia de la Unión Europea, haciendo extensión de la cosa juzgada material en los procesos colectivos a los individuales con igual objeto procesal y mismo demandado.

13 Memoria año 2018 elevada al Gobierno por la Fiscal General del Estado Excma. Sra. Doña María José Segarra Crespo. Propuesta de modificación del procedimiento colectivo de consumo. Pág.1277. 
El capítulo de la competencia territorial de los artículos 50 y 51 de la LEC, a propuesta de la Fiscalía de la Comunidad Autónoma de Andalucía, de la que también se hace eco la Fiscalía General, debe aclararse el fuero en favor del domicilio del consumidor y, ante la engorrosa interpretación a que puede dar lugar la norma actual, aplicar el principio de "favorecimiento del consumidor proclamado en el art. 51 de la Constitución"

Con relación a los elevados costes de comparecencia del consumidor en los procedimientos colectivos, recuerda la jurisprudencia general del TJUE sobre el carácter desincentivador de tales costes y su repercusión en el ejercicio del derecho a una buena defensa o el mero hecho de la interposición de recursos.

Capítulo aparte merece la referencia a los principios inspiradores de orden público y actuación de oficio que deben ser incorporados "expresamente" en esta nueva regulación de los procedimientos colectivos de consumo y ya aplicados tanto por el Tribunal de Justicia de la Unión Europea como por nuestro Tribunal Supremo, en lugar de los tradicionales de justicia rogada y aportación de parte

Creo que la crítica no es compleja pues se trata de ideas generales por las que, la Fiscalía General del Estado, sólo se hace eco de la propuesta de modificación que hace el Parlamento Europeo y el Consejo relativa a la nueva regulación que se pretende sobre acciones de representación para la protección de los intereses colectivos de los consumidores en base a dos claves deficitarias que se destacan sobre la Directiva en vigor: 1) Los efectos limitados de compensación a favor de los consumidores por la aplicación de las sentencias en resoluciones favorables sobre acciones de cesación y 2) Coste y duración de los procedimientos. ${ }^{14}$

14 Las líneas básicas de la propuesta de reforma son: 1) Ámbito de aplicación. Ampliar su ámbito de aplicación permitiendo que el procedimiento tenga capacidad de reacción ante infracciones en los "sectores económicos en los que las prácticas ilícitas de los comerciantes pueden afectar a un gran número de consumidores."2) Nueva habilitación para el ejercicio de las acciones de representación por parte de las entidades designadas por los Estados Miembros las que deberán cumplir unos criterios mínimos de reputación ("estar debidamente establecidas; ser entidades sin ánimo de lucro y tener un interés legítimo en garantizar el cumplimiento de la legislación pertinente de la UE") y para el ejercicio de acciones de reparación o resarcitorias, demostrar capacidad financiera y origen de fondos mínimos que apoyen la acción.3) Eficiencia en el procedimiento exigiendo a los Estados una "diligencia debida" y costas procesales adecuadas, comunicación y beneficio colectivo de la sentencia a todos los consumidores afectados y una especie de título ejecutivo para iniciar posterior acción resarcitoria, o como define la propia propuesta, "constituirán una prueba irrefutable en las acciones de reparación (dentro del mismo Estado miembro) o una presunción refutable de que se ha producido la infracción (para los 


\section{CONCLUSIÓN.}

La creación de nuevos marcos de relaciones contractuales entre las que se mueven los consumidores contra los grandes distribuidores de bienes de primera necesidad hace que la protección pública aparezca como necesidad ante situaciones de vulnerabilidad, de partida o provocadas, de determinados individuos titulares de derechos fundamentales. El Ministerio Fiscal ha tenido que modificar su papel judicial ante estas situaciones de inferioridad, subordinación e indefensión, desplegando una actuación protectora ante lo que llamamos consumidor vulnerable. Las Instituciones públicas, Estado, Comunidades Autónomas y Unión Europea han regulado determinados ámbitos procesales para el despliegue de esta tutela cautelar que necesita de nuevo impulso fomentando las acciones colectivas como base de partida a una nueva jurisprudencia que vaya atendiendo las venideras formas de relación consumista del siglo XXI.

\footnotetext{
casos presentados en otro Estado miembro). Fomento de acuerdos colectivos extraprocesales.4) Acumulación de acciones y nueva tipificación de acciones. Se permitirá a las Entidades habilitadas interponer acciones de representación para obtener distintas medidas cautelares o definitivas clásicas dentro de las acciones colectivas y otras para obtener un "orden" de reparación para obtener del infractor la obligación de indemnización, arreglo, sustitución, reducción de precios, resolución del contrato o reembolso del precio pagado, según proceda. Y novedoso, flexibilidad para los Estados en casos de resarcimiento complejo por las características de la cuantificación del perjuicio individual con la posibilidad de facultar a los órganos judiciales para decidir "si, en lugar de una orden de reparación, dictan una resolución declarativa en relación con la responsabilidad del comerciante frente a los consumidores perjudicados por una infracción del Derecho de la Unión, en la que podrán basarse directamente acciones de reparación subsiguientes." No entrarían en esta flexibilización los casos frecuentes de daños masivos y los de escasa cuantía donde la reparación debería destinarse a un objetivo público al servicio de los intereses colectivos de los consumidores. 5) Buscar un equilibrio entre facilitar el acceso a la justicia y garantizar otras salvaguardas frente a litigios abusivos exigiendo a las entidades habilitadas unos mínimos de reputación como salvaguardia frente a acciones "frívolas" que, a su vez, tanto si se llegan a cuerdos entre partes, deben ser revisadas por el órgano jurisdiccional.
} 


\section{BIBLIOGRAFIA Y FUENTES}

\section{LEGISLACIÓN:}

Real decreto 536/2017, de 26 de mayo, por el que se crea y regula la comisión de seguimiento, control y evaluación prevista en el real decreto-ley 1/2017, de 20 de enero, de medidas urgentes de protección de consumidores en materia de cláusulas suelo, y por el que se modifica el artículo 6 del real decreto 877/2015, de 2 de octubre, de desarrollo de la ley 26/2013, de 27 de diciembre, de cajas de ahorro y fundaciones bancarias. Fecha de Entrada en Vigor28 de Mayo de 2017. MarginalBOE-A-2017-5864.

Propuesta de Reglamento del Parlamento Europeo y del Consejo sobre el Programa de Consumidores 2014-2020 de 9.11.2011. $\operatorname{COM}(2011) 707$ final. 2011/0340 (COD).

Dictamen del Comité Económico y Social Europeo sobre la «Propuesta de Reglamento del Parlamento Europeo y del Consejo sobre el Programa de Consumidores 2014-2020» de 21.6.2012. [COM(2011) 707 final - 2011/0340 (COD)]. (2012/C 181/16).

Reglamento (UE) n ${ }^{\circ}$ 254/2014 del Parlamento Europeo y del Consejo de 26 de febrero de 2014 sobre el Programa plurianual de Consumidores para el período 2014-2020 y por el que se deroga la Decisión n o 1926/2006/CE.

Dictamen del Comité de las Regiones - «El programa de consumidores 2014-2020» de 27.7.2012. (2012/C 225/17).

Ley 5/2019, de 15 de marzo, reguladora de los contratos de crédito inmobiliario.

Jefatura del Estado. «BOE» núm. 65, de 16 de marzo de 2019. Referencia: BOE-A-2019-3814.

Comunicación de la Comisión Europa 2020. Una estrategia para un crecimiento inteligente, sostenible e integrador de 3.3.2010. $\operatorname{COM}(2010) 2020$ final.

Libro Verde sobre la protección de los consumidores en la Unión Europea de 2.10.2001. COM(2001) 531 final

Decisión no 283/1999/CE del Parlamento Europeo y del Consejo de 25 de enero de 1999 por la que se establece un marco general para las actividades comunitarias en favor de los consumidores.

Reglamento (UE) 2017/2394 del Parlamento Europeo y del Consejo de 12 de diciembre de 2017 sobre la cooperación entre las autori- 
dades nacionales responsables de la aplicación de la legislación en materia de protección de los consumidores y por el que se deroga el Reglamento (CE) n. o 2006/2004.

Real Decreto 897/2017, de 6 de octubre, por el que se regula la figura del consumidor vulnerable, el bono social y otras medidas de protección para los consumidores domésticos de energía eléctrica. Ministerio de Energía, Turismo y Agenda Digital. «BOE» núm. 242, de 7 de octubre de 2017. Referencia: BOE-A-2017-11505.

Directiva 2014/17/UE del Parlamento Europeo y del Consejo de 4 de febrero de 2014 sobre los contratos de crédito celebrados con los consumidores para bienes inmuebles de uso residencial y por la que se modifican las Directivas 2008/48/CE y 2013/36/UE y el Reglamento (UE) n o 1093/2010.

Comunicación de la Comisión al Parlamento Europeo, al Consejo y al Comité Económico y Social sobre Un Nuevo Marco para los Consumidores. Bruselas, 11.4.2018 COM(2018) 183 final.

Propuesta de Directiva del Parlamento Europeo y del Consejo relativa a las acciones de representación para la protección de los intereses colectivos de los consumidores y por la que se deroga la Directiva 2009/22/CE. Bruselas, 11.4.2018 COM(2018) 184 final 2018/0089 (COD).

Dictamen del Comité Económico y Social Europeo sobre a) «Propuesta de Directiva del Parlamento Europeo y del Consejo relativa a las acciones de representación para la protección de los intereses colectivos de los consumidores y por la que se deroga la Directiva 2009/22/CE»[COM(2018) 184 final - 2018/0089 (COD)]

Código del Ministerio Fiscal. Selección y ordenación: Fiscalía General del Estado. Edición actualizada a 13 de mayo de 2019. BOE.

Reglamento interno y de Procedimiento del Tribunal de Justicia de la Unión Europea. Diario Oficial de la Unión Europea de 29.09.2012. L 265/1. (Cuestión prejudicial pág. 93 y ss.)

Instrucción 1/2016 de la Fiscalía General del Estado, sobre la intervención del Fiscal en las Cuestiones Prejudiciales Europeas. Emitida por la Fiscalía General del Estado el 7 de enero de 2016.

Circular 2/2010 de la Fiscalía General del Estado, acerca dela intervención del Minsiterio Fiscal en el Orden Civil para la Protección de los Consumidores y Usuarios. 
Circular 2/2018 de la Fiscalía General del Estado, sobre nuevas directrices en materia de protección jurídica de los derechos de los consumidores y usuarios.

Comunicación de la Comisión Directrices sobre la interpretación y la aplicación de la Directiva 93/13/CEE del Consejo sobre las cláusulas abusivas en los contratos celebrados con los consumidores de 27.09.3019. (2019/C 323/04).

Memoria de la Fiscalía General del Estado. Año 16 y presentada al inicio del año judicial 17 por el Fiscal General del Estado Excmo. Sr. D. José Manuel Maza Martín.

Memoria de la Fiscalía General del Estado. Año 17 y presentada al inicio del año judicial 18 por la Fiscal General del Estado Excma. Sra. D ${ }^{a}$ María José Segarra Crespo.

Memoria de la Fiscalía General del Estado. Año 18 y presentada al inicio del año judicial 19 por la Fiscal General del Estado Excma. Sra. Da María José Segarra Crespo.

\section{ARTÍCULOS:}

GONZÁLEZ VAQUÉ CONSEJERO, Luis., Dirección General de Mercado Interior y Servicios, Comisión Europea, Bruselas. La Noción de Consumidor en el Derecho Comunitario de Consumo. Versión anotada y puesta al día del documento de trabajo sobre el mismo tema distribuido por el autor en el marco del XXVIII Curso sobre la Unión Europea organizado por el Patronat Català Pro Europa en colaboración con la Secretaría de Estado para la UE y la Escuela Diplomática del Ministerio de Asuntos Exteriores y de Cooperación. Barcelona, septiembre-diciembre de 2005.

FERNÁNDEZ LE GAL, Annaïck., La intervención del ministerio fiscal en defensa del interés público en procesos no penales. Especial atención a su labor de promoción y defensa del interés social y los derechos de los ciudadanos. Revista Jurídica de los Derechos Sociales. Enero-junio 2014. (Pág.106-137).

HERNÁNDEZ DÍAZ-AMBRONA, $\mathrm{M}^{\mathrm{a}}$ Dolores., El hipotecante no deudor y el consumidor en materia de energía eléctrica como consumidores vulnerables. Revista Ministerio fiscal $\mathrm{n}^{\circ} 4$. Año 17. Pág. 76-93. 
CAMPOY-MIÑARRO, Manuel., El papel del Ministerio Fiscal en la protección jurídica de los consumidores. Revista Ministerio fiscal nº 4. Año 17. Pág. 41-59.

\section{JURISPRUDENCIA:}

Sentencia Tribunal Supremo. Sala de lo Civil $N^{\circ} 367 / 2017$ del 08/06/2017. Ponente: Rafael Saraza Jimena. Acción de nulidad de cláusula suelo en préstamo hipotecario. Control de transparencia. Importancia de la información precontractual.

AUTO núm. 584/2018. Sección n ${ }^{\circ} 5$ de la Audiencia Provincial de Zaragoza de 12 de Diciembre de 2018. Cuestión Prejudicial sobre el Recurso de Apelación 247/2018.

Sentencia del Tribunal de Justicia de la Unión Europea (Sala Primera) de 14 de abril de 2016 ASUNTOS ACUMULADOS C-381/14 Y C-385/14 SALES SINUÉS Y DRAME BA. Procedimiento prejudicial - Directiva 93/13/ CEE. 
